\title{
Fetal Transcerebellar Diameter/ Abdominal Circumference Ratio as a Gestational Age Independent Parameter for Fetal Growth
}

\author{
Jha A, ${ }^{1}$ Joshi B, ${ }^{2}$ Pradhan $\mathbf{S}^{2}$ \\ ${ }^{1}$ Department of Radiodiagnosis and Medical Imaging, KIST Medical College Teaching Hospital, Lalitpur, ${ }^{2}$ Department of \\ Radiodiagnosis and Imaging, Institute of Medicine, Tribhuwan University Teaching Hospital, Maharagunj, Nepal
}

Received: March 05, 2014; Accepted: August 15, 2014

Aims: The purpose of this study was to evaluate accuracy of trans-cerebellar diameter / abdominal circumference (TCD/ AC) ratio to assess fetal growth. The ratio of TCD with head circumference (HC) and biparietal diameter (BPD) was also determined.

Methods: This was a prospective cross-sectional study involving 442 women with uncomplicated singleton gestation between 15-40 weeks. Protocol included obtaining the BPD, HC, TCD and AC in conventional planes and obtaining ratio of TCD with other biometric parameters.

Results: We were able to visualize the cerebellum in about $93 \%$ of scans. The TCD/ AC ratio remained nearly constant throughout gestational age and was 0.138 . The mean TCD/HC ratio was 0.124 and mean TCD/BPD ratio was 0.476

Conclusions: $\mathrm{TCD} / \mathrm{HC}$ and $\mathrm{TCD} / \mathrm{BPD}$ ratio showed a small increase towards the completion of gestation while $\mathrm{TCD} / \mathrm{AC}$ ratio remained nearly constant throughout gestational age. TCD/AC ratio is reliable as a gestational age independent parameter of fetal growth.

Keywords: fetal biometry; fetal cerebellum; obstetric ultrasound; trans-cerebellar diameter.

\section{INTRODUCTION}

The limitation of biometric parameters in practice arises when evaluating the status of fetal growth with unknown gestational age: whether the fetal growth is appropriate or restricted? The cerebellum, by virtue of its position in the posterior fossa, is affected least by extrinsic pressure and variations in head shape. ${ }^{1}$ Blood supply from posterior circulation leads to cerebellar sparing effect in growth restriction. ${ }^{2}$ Thus, the cerebellar size tends to remain unaffected or minimally affected in mild and moderate growth restriction. The fetal liver is affected early in growth restriction due to depletion of the glycogen stores leading to reduced abdominal circumference (AC). ${ }^{3}$

\section{CORRESPONDENCE}

Dr Anamika Jha

Department of Radiodiagnosis and Medical Imaging, KIST Medical College Teaching Hospital, Lalitpur, Nepal.

E-mail: anamikajha dr@hotmail.com

Phone: +977-984969 $\overline{4} 4875$
Theoretically, the trans-cerebellar diameter (TCD)/ $\mathrm{AC}$ ratio should be a good parameter for detecting intrauterine growth restriction (IUGR) because it is composed of parameters least and most sensitive to fetal growth, with an increased ratio reflecting IUGR.

Various age-independent body ratios like HC/AC and $\mathrm{FL} / \mathrm{AC}$ have been found useful to diagnose IUGR, which may however, be of limited value in symmetric IUGR. $^{4-7}$ Good correlation of TCD/AC ratio with GA has been demonstrated. ${ }^{3,4,7-9}$ While many studies show that TCD/AC can be used as a predictor of fetal growth, some suggest that cerebellar size is reduced in size in severe IUGR and so this ratio may not be of use in these cases. ${ }^{5,8,10,11} \mathrm{TCD} / \mathrm{HC}$ ratio was found to be relatively constant throughout gestation by Snijders and Nicolaides. ${ }^{12}$ Our study evaluated reliability of $\mathrm{TCD} / \mathrm{AC}$ ratio to assess fetal growth and determines ratio of TCD with other biometric parameters. 


\section{METHODS}

This was a prospective cross sectional study involving 442 uncomplicated singleton pregnancies between 15-40 weeks of gestation as determined by reliable last menstrual period or ultrasound examination before 15 weeks of gestation, who were referred for routine obstetric scan, without known complications in the current pregnancy, without known risk factors of adverse pregnancy outcome and willingness to participate in the study. Of these 442 cases, the posterior fossa could not be well visualised in 31 cases, either due to obesity or in late third trimester. So, these were excluded and trans-cerebellar view obtained in 411 cases (93\%). This study was done in the Department of Radiology and Imaging, Tribhuwan University Teaching Hospital from September 2008 to August 2009.

The obstetric scan was done and required biometric parameters obtained. Measurements of the BPD and $\mathrm{HC}$ were obtained in all cases after obtaining conventional transverse axial plane of the fetal head showing a "arrow like" appearance with a central midline echo broken in the anterior third by the cavum septum pellucidi and the frontal horns of the lateral ventricles (feathers). ${ }^{13}$ Slight rotation of the transducer from the conventional plane for obtaining $\mathrm{HC}$ demonstrated the contents of the posterior fossa and the TCD was measured as the widest diameter of the cerebellum. ${ }^{14} \mathrm{FL}$ and $\mathrm{AC}$ were measured in conventional planes. ${ }^{8,13}$ The TCD/AC, TCD/BPD and TCD/HC ratios were obtained. Data were compiled and analysed using standard statistical analysis. SPSS 11.5 was utilized for the data analysis to calculate ratios, correlations and regression formulas.

\section{RESULTS}

The subjects ranged from 17 to 39 years, mean age being 25 years. $55.7 \%(\mathrm{n}=229)$ were nulliparous and $44.3 \%(\mathrm{n}=182)$ multiparous. The mean gestational age was 26.47 weeks. Most of the cases were between 18 to 22 weeks (Figure 1 ).

TCD showed strong correlation with the other biometric parameters (Table 1). All the ratios evaluated, i.e. TCD/AC, TCD/HC and TCD/BPD showed good correlation with GA with $\mathrm{P}$ value less than 0.001 . The mean $\mathrm{TCD} / \mathrm{AC}$ ratio was 0.138 and it showed a very small increase towards the last trimester i.e. 0.15 at $39-40$ weeks (Figure 2). The mean TCD/HC ratio was 0.124 and showed a small increase from 0.12 to 0.15 from 15 weeks to 39 weeks along with maximum positive correlation with GA, $\mathrm{r}=0.78$. The mean TCD/BPD ratio was 0.476 and it showed an increasing trend from 0.45 at $15-16$ weeks to 0.57 in the last week.
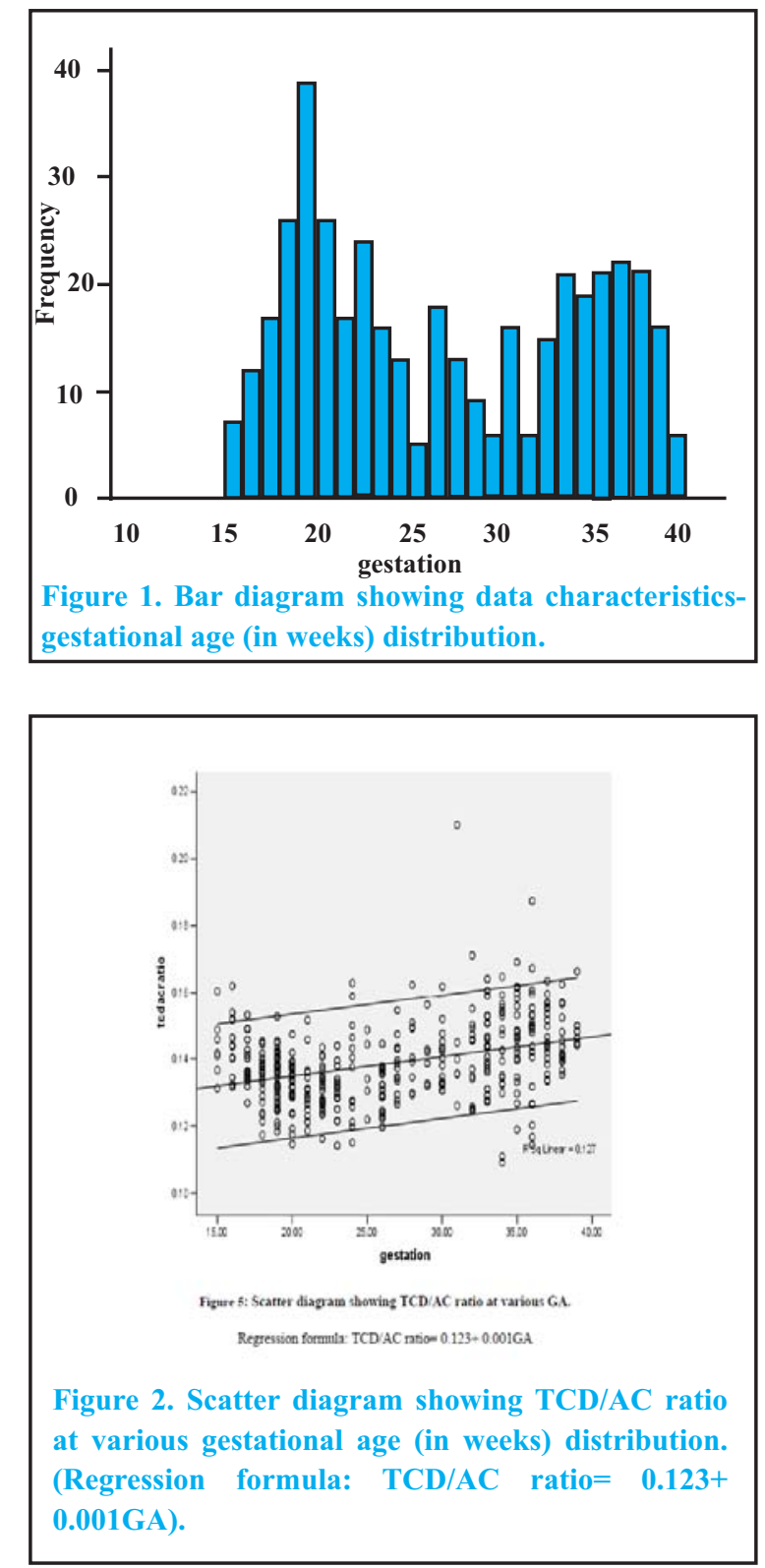
Table 1. Correlation of TCD with other biometric parameters $(n=411)$.

\begin{tabular}{|crc|}
\hline Parameter & Correlation & P Value \\
AC & 0.972 & 0.001 \\
HC & 0.962 & 0.001 \\
BPD & 0.961 & 0.001 \\
\hline
\end{tabular}

Table 2. Mean and median TCD/AC values in various studies $(n=411)$.

\begin{tabular}{|lll|}
\hline Study & Mean & Median \\
Campbell et al & \\
Malik et al $^{16}$ & 0.137 & 0.136 \\
Snijders et al $^{12}$ & 0.141 & - \\
Meyer et al $^{18}$ & - & 0.137 \\
Haller et al $^{10}$ & 0.136 & 0.137 \\
Present study & 0.144 & - \\
\hline
\end{tabular}

\section{DISCUSSION}

Multiple standard biometric measurements are used in practice to define the growth status of the fetus and identify IUGR. These are of limited value with uncertain GA, where GA independent parameters should be helpful. All the ratios evaluated in our study show high correlation with GA and may be used as GA independent parameter. $\mathrm{TCD} / \mathrm{AC}$ ratio showed least variation and so may be the most GAindependent parameter. Comparison with other studies is shown in table 2. ${ }^{4,10,12,15,16}$

Meyer et $\mathrm{al}^{16}$ found strong correlation existed between GA and TCD and AC, mean TCD/AC ratio being 0.136 (median $=0.137$ ) and remained constant throughout pregnancy. In this study also, the ratio with respect to GA. Haller et $\mathrm{al}^{10}$ also found strong correlation between TCD and AC ( $\mathrm{r}=$ $0.87251)$. Snijders et $\mathrm{al}^{12}$ found the $\mathrm{TCD} / \mathrm{HC}$ ratio to be relatively constant throughout gestation: 0.12 at 15 weeks, 0.12 at 28 weeks and again rose to 0.13 at 39 weeks. We also derived similar $\mathrm{TCD} / \mathrm{HC}$ ratio, which was relatively constant ranging from 0.12 at 15 weeks, 0.13 at 28 weeks and 0.15 at 38 weeks. To the best of our knowledge, TCD/BPD has not been evaluated in any other study. We found that the ratio has a narrow range from 0.46 at 15 weeks to 0.55 at 38 weeks.
Some studies show that severe growth restriction i.e. birth weight below the third centile, may be associated with normal TCD/AC values, probably due to either reduced cerebellar growth in severe growth restriction or the presence of a genetically small fetus and therefore a small cerebellum..$^{5,8,17,18}$

The TCD/AC relationship can be helpful in recognizing abnormal fetal growth, with ratio above the upper limit being suspicious of growth restriction. This ratio would be more significant when GA is not known. In a small percentage of cases, the evaluation of TCD may be limited by the inability to visualize cerebellum, where other views of the cerebellum, like coronal may serve as alternate to the transaxial. ${ }^{19}$ The ratio of TCD with HC and BPD, in spite of good correlation with GA and being relatively constant throughout GA, may not be reliable as $\mathrm{HC}$ and BPD are not as sensitive as $\mathrm{AC}$ to growth restriction and are affected by extrinsic factors. We hope further studies with larger sample size and in IUGR fetuses will be done, to validate the reliability of these ratios, especially, in severe symmetric IUGR.

\section{CONCLUSIONS}

The TCD/HC and TCD/BPD ratio showed a small increase towards the completion of gestation while $\mathrm{TCD} / \mathrm{AC}$ ratio remained nearly constant across the gestational age with a mean value of 0.138 . We recommend that $\mathrm{TCD} / \mathrm{AC}$ should be considered an integral part of obstetric scan and should be routinely assessed in level one scan.

\section{DISCLOSURE}

The authors report no conflicts of interest in this work.

No violation of human rights and safety.

Funding: Nil 


\section{REFERENCES}

1. Hashimoto K, Shimizu T, Shimoya K, Kanzaki T, Clapp JE Murata Y. Fetal cerebellum: US appearance with advancing gestational age. Radiology. 2001;221(1):70-4.

2. Babcook JC, Chong BW, Salamat MS, Ellis WG, Goldstein RB. Sonographic anatomy of the developing cerebellum: normal embryology can resemble pathology. AJR 1996;166:427-33.

3. Haller H, Petrovic O, Rukavina B. Fetal transverse cerebella diameter/ abdominal circumference ratio in assessing fetal size. Int J Gynaecol Obstet. 1995;50(2):159-63.

4. Campbell S, Thomas A. Ultrasound measurement of the fetal head to abdomen circumference ratio in the assessment of growth retardation. BJOG. 1977;84:165-74.

5. Campbell WA, Nardi DR, Vintzileos AM, John F, Turne GW, Egan JFX. Transverse cerebellar diameter/ abdominal circumference ratio throughout pregnancy: a gestational age independent method to assess fetal growth. Obstet Gynecol. 1991;77:893-9.

6. Hadlock FP, Deter RL, Harrist RB, Roecker E, Park SK A date-independent predictor of intra-uterine growth retardation: femur length/abdominal circumference ratio. Am J Roetgenol. 1983;141:979- 84.

7. Reece EA, Goldstein I, Pilu G, Hobbins JC. Fetal cerebellar growth unaffected by intrauterine growth retardation: a new parameter for prenatal diagnosis. Am J Obstet Gynecol. 1987; $157: 632-8$

8. Snijders RJM, Richard HB, De Courcy-Wheeler, Nicolaides $\mathrm{KH}$. Intrauterine growth retardation and fetal transcerebellar diameter. Prenatal Diagnosis. 1995;14:1101- 5.

9. Tongsong T, Wanapirak C, Thonpadungroj T. Sonographic diagnosis of intrauterine growth retardation by fetal transcerebellar diameter/abdominal circumference ratio. Int J Gynaecol Obstet. 1999;66:1-5.

10. Estroff JA, Scott MR, Benacerraf BR. Dandy- Walker variant: prenatal sonographic features and clinical outcome. Radiology. 1992;185:755- 63
11. Hill L, Guzick D, Rivello D, Hixon J, Peterson C. The transverse cerebellar diameter cannot be used to assess gestational age in the small for gestational age fetus. Obstet Gynecol. 1990;75:329-33.

12. Snijders RJM, Nicolaides KH. Fetal biometry at $14-40$ weeks of gestation. Ultrasound Obstet Gynecol. 1994;4:34-8.

13. Galan HL, Pandipati S, Filly RA. Ultrasound evaluation of fetal biometry and normal and abnormal fetal growth. In: Peter W Callen, editors. Ultrasonography in obstetrics and gynaecology. 5th ed. Pennsylvania: W.B. Saunders Company; 2008. p. 225-61.

14. Rakic P, Sidman RL. Histogenesis of cortical layers in human cerebellum, particularly the lamina dissecans. J Comp Neurol. 1970;139(4):473-500.

15. Malik R, Pandya VK, Shrivastava P. Gestational age estimation using transcerebellar diameter with grading of fetal cerebellum and evaluation of transverse cerebellar diameter/ abdominal circumference ratio as a gestational age independent parameter. IJRI. 2003;13:95-7.

16. Meyer WJ, Gauthier DW, Goldenberg B, Santolaya J, Sipos J, Cattledge F. The fetal transverse cerebellar diameter/ abdominal circumference ratio: a gestational age independent method of assessing the fetal size. J Ultrasound Med. 1993;12(7):379- 82 .

17. Meyer WJ, Gauthier D, Viswanathan R, Sipos J. Ultrasonographic detection of abnormal fetal growth with the gestational age-independent, transverse cerebellar diameter/ abdominal circumference ratio. Am J Obstet Gynecol. 1994;171(4):1057-63.

18. Goldstein I, Reece EA, Pilu G, Bovicelli L, Hobbins JC. Cerebellar measurements with ultrasonography in the evaluation of fetal growth and development. Am J Obstet Gynecol. 1987;156(5):1065-9.

19. Kofina AD, Simon NV, King K. Comparison of foetal cerebellar measurements by two different techniques. J Ultrasound Med. 1992;11:257-63. 